4 El Sammaa M, Linthicum FH, House HP, House JW. Calcitonin as treatment for hearing loss in Paget's disease. Am J Otol 1986;7:241-43

5 Gennari C. Diphosphonate therapy in deafness associated with Paget's disease. BMJ 1975; 1:331

6 Donath J, Krasznai M, Fornet B, Gergely P, Poor G. Effect of bisphosphonate treatment in patients with Paget's disease of the skull. Rheumatology 2004;43:89-94

7 Monsell EM, Cody DD, Bone HG, Divine GW. Hearing loss as a complication of Paget's disease of bone. $J$ Bone Mineral Res 1999;14(suppl 2):92-5

\section{Topical ciprofloxacin can delay recovery from viral ocular surface infection}

\section{A Patwardhan MS FRCSEd M Khan MBBS}

J R Soc Med 2005;98:274-275

If prescribed for a viral ocular infection, topical ciprofloxacin is more likely to do harm than good.

\section{CASE HISTORY}

A previously fit and healthy man of 27 attended with painful red eyes. He also reported general malaise and sore throat. For the past week he had been treating his eyes with ciprofloxacin $0.3 \%$ ophthalmic solution every two hours on the advice of his general practitioner, and it was a worsening of his eye symptoms that caused him to come to eye casualty. There was no previous history of eye disorder and he was using no other medications. On examination, visual acuities were 6/60 in the right eye and 6/36 in the left eye. Both conjunctivae showed a severe follicular reaction, and fluffy white precipitates were seen adhering to the surface of both corneas (Figure 1). There was mild pharyngitis but lymphadenopathy was absent. The clinical evidence was suggestive of pharyngo-conjunctival fever. When the infiltrates were scraped under local anaesthesia, subepithelial infiltrates typical of adenoviral keratoconjunctivitis were clearly visible (Figure 2). The patient was asked to stop topical ciprofloxacin and was treated with only tear substitute. Six weeks later visual acuities were $6 / 6$ and ocular examination revealed nothing abnormal. On electronmicroscopy the corneal scrapings showed needle-shaped crystals and viral cultures grew adenovirus type 3; the bacterial cultures were negative.

Department of Ophthalmology, Royal Shrewsbury Hospital, Mytton Oak Road, Shrewsbury SY3 8XQ, UK

Correspondence to: Mr A Patwardhan

E-mail: apatwa@hotmail.com

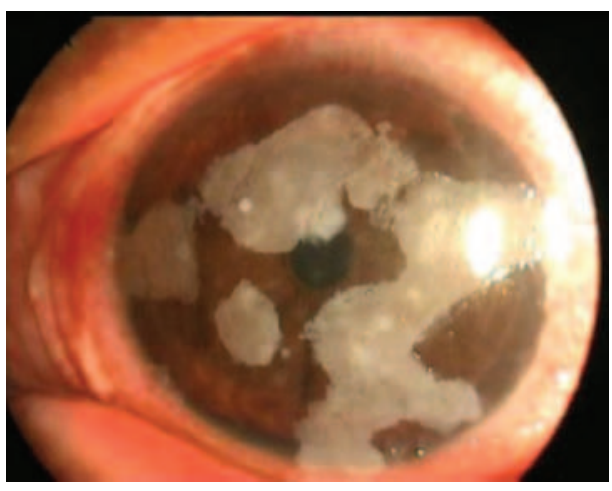

Figure 1 Slit lamp photograph showing corneal epithelial precipitates (in colour online)

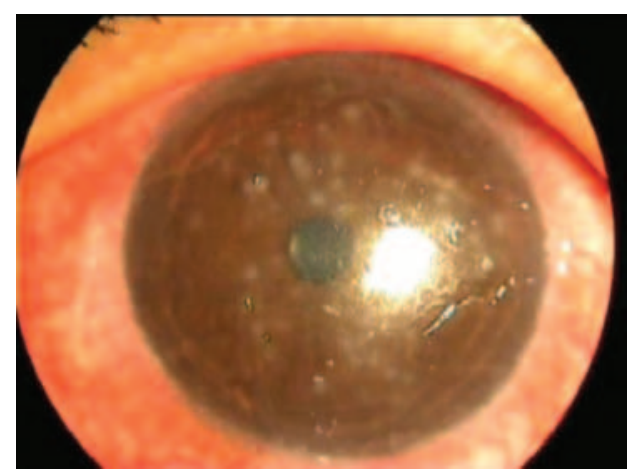

Figure 2 Same patient after corneal scraping. Note subepithelial infiltrates as seen in adenoviral keratoconjunctivitis (in colour online)

\section{COMMENT}

The formation of white crystalline precipitates is a well known property of ciprofloxacin when it is used for treatment of bacterial ulcer. ${ }^{1-3}$ These precipitates, though sometimes troublesome, have the advantage of yielding high local concentrations of the drug and their presence is beneficial in bacterial keratitis. ${ }^{4}$ The reason for their appearance is that topical ciprofloxacin is made up at low $\mathrm{pH}$ to discourage precipitation, and the $\mathrm{pH}$ rises when the solution meets the tear film. This is not true of topical ofloxacin. Sometimes ciprofloxacin crystals develop even in the original container, blocking the nozzle track. ${ }^{5}$ Adenoviral keratoconjunctivitis, as seen in the present patient, resolves spontaneously within 10-14 days. ${ }^{6}$ Topical lubricants, and in some cases topical corticosteroids, may be useful, but antibiotic therapy has no role. ${ }^{6}$ The irregular surface formed by precipitates of ciprofloxacin causes discomfort, reduces visual acuity and delays recovery.

\section{REFERENCES}

1 Eiferman RA, Snyder JP, Nordquist RE. Ciprofloxacin micro precipitates and macro precipitates in the human corneal epithelium. J Cataract Refract Surg 2001;27:1701-2

2 Leibowitz HM. Clinical evaluation of ciprofloxacin $0.3 \%$ ophthalmic solution for treatment of bacterial keratitis. Am J Ophthalmol 1991;112:34-47S 
3 Wilhelmus KR, Hynduik RA, Caldwell DR, Abshire RL, Folkens AJ, Godio LB, for Ciprofloxacin Ointment/Bacterial Study Group. 0.3\% ciprofloxacin ointment in the treatment of bacterial keratitis. Arch Ophthalmol 1993;111:1210-18

4 Madhavan HN, Rao SK, Joseph PR, Sulochana KN. Antibacterial activity of the white precipitate formed on the corneal surface after treatment with ciprofloxacin ophthalmic solution. Cornea 1999; 18:549-52

5 John T. Scanning electron microscopic study of a Ciloxan bottle blocked by ciprofloxacin crystals. Eye 2001;15:786-8

6 Kaufman HE, Barron BA, McDonald MB, Kaufman SC. Companion Handbook to the Cornea, 2nd edn. London: Butterworth-Heinemann, 2000:243-4

\section{Tortuous common carotid artery as a cause of dysphagia}

\author{
Ashish Gupta MRCS Marc C Winslet MS FRCS
}

J R Soc Med 2005;98:275-276

Dysphagia lusoria can be caused by any type of vascular ring ${ }^{1}$ but is commonly associated with an aberrant left or right subclavian artery, a right aortic arch or a common carotid artery aneurysm. ${ }^{2}$

\section{CASE HISTORY}

A woman of 82 was seen in outpatients after eight weeks of mild postcibal epigastric discomfort. She also gave a long history of dysphagia. 18 years previously, dilatation of an oesophageal stricture had been unsuccessful and the dysphagia had continued - only to solids, with occasional episodes of food bolus obstruction and difficulty in swallowing certain tablets. There had been no weight loss or change in appetite.

Her medical history included polymyalgia rheumatica, for which she was on steroids, and hypertrophic cardiomyopathy. She had smoked till the age of 40. On examination there was no pulsatile mass in the neck and the carotid pulsations on both sides were normal. A barium swallow showed a tight stricture of the lower cervical oesophagus with dilatation of the pharynx and the upper cervical oesophagus proximal to the stricture. The stomach and the duodenum were normal. The stricture had a smooth margin consistent with an extrinsic compression (Figure 1). MRI of the neck showed a tortuous right common carotid artery indenting the oesophagus (Figures 2 and 3). Upper gastrointestinal endoscopy was not performed because of the patient's poor cardiac status.

University Department of Surgery, Royal Free Hospital, Hampstead, London NW3 2QG, UK

Correspondence to: Professor Marc C Winslet

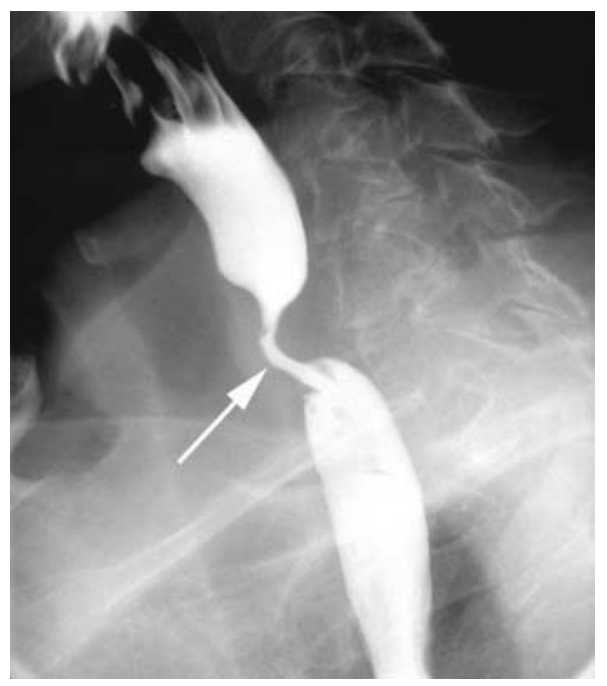

Figure 1 Barium swallow showing tight stricture of cervical oesophagus with proximal dilatation

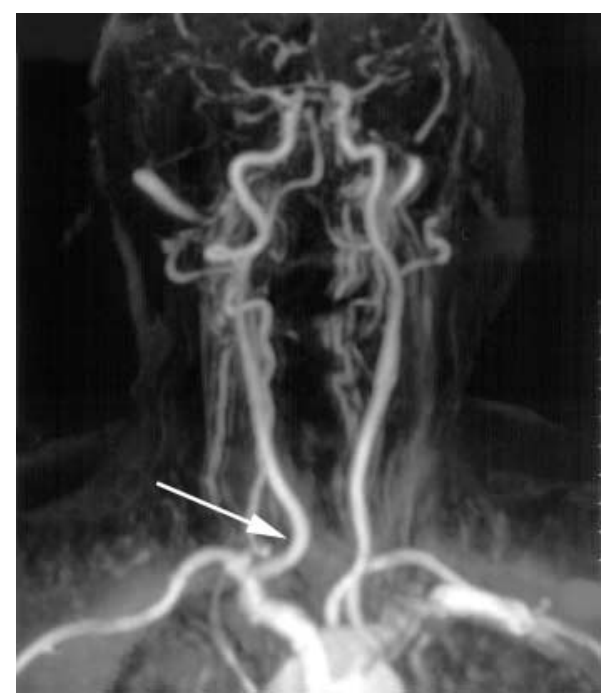

Figure 2 MR angiogram showing tortuous right common carotid artery

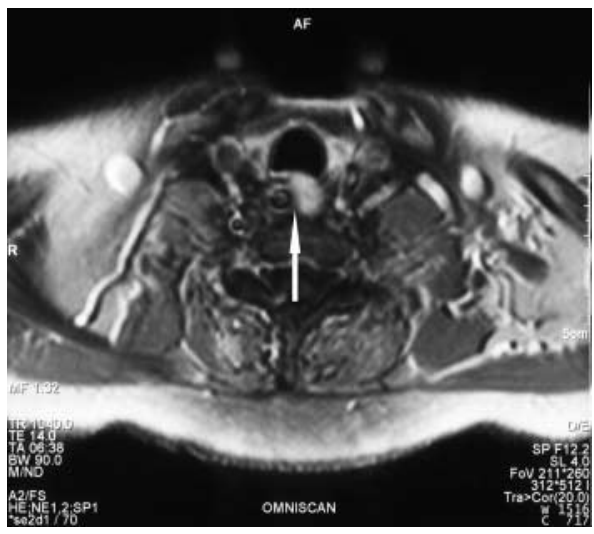

Figure 3 Axial MRI showing right common carotid artery displacing oesophagus to left 